\title{
UNA COMPANY TOWN CASI EXTINTA DE LA ERA INDUSTRIAL EN EL TRIUNFO BAJA CALIFORNIA SUR: Trazados urbanos y vestigios en El Triunfo y San Antonio 1866
}

\author{
Enrique Esteban Gómez Cavazos \\ Universitat Politécnica de Catalunya \\ Directores: Joaquín Sabaté Bel y Melisa Pesoa Marcilla \\ eecavazos@hotmail.com
}

\begin{abstract}
RESUMEN
Las concesiones de explotación minera en la península de Baja California desde la segunda mitad del siglo XIX, se pueden considerar herramientas que impulsan el desarrollo de las regiones del Norte de México. Obedecen a la intención del gobierno mexicano de poblar y estructurar esa larga península, tan alejada del centro del país. El capital extranjero, en este caso inglés y norteamericano, es una pieza clave para implementar un centro minero moderno de gran importancia en la costa del Pacífico, que llega a consolidar un núcleo urbano productivo para la extracción, procesamiento y exportación de minerales como oro y plata, localizados en el extremo sur de la península.

Este texto analiza el origen y florecimiento de estas poblaciones y los proyectos de las compañías extranjeras, su estado actual y su legado. Se intenta valorar hasta que punto se consolida su traza y ver con que elementos de importancia cuenta este territorio, defendiendo la hipótesis de que contiene suficientes recursos para valorizar su identidad industrial.
\end{abstract}

Palabras clave: concesión territorial, vestigios industriales, company town

\begin{abstract}
The mining explotaition concessions in the peninsula of Baja California since the second half of the nineteenth century, can be considered tools to improve the development of northern regions of Mexico. They follow the intention of the Mexican government to populate and structure this long peninsula far from the center of the country. Foreign capital, in this case English and North American, are the key to implement a modern mining center of great importance in the Pacific coast, which comes to consolidate a productive urban core for the extraction, processing and export of minerals such as gold and silver, located in the southern of the peninsula.

This text analyses the origins and the flowering of these populations and the projects of the foreign companies, their current status and their legacy. We try to evaluate how they consolidate a historic ocupation and to see with what elements of importance this territory counts, defending the hypothesis that it contains enough industrial resources to highlight its industrial identity.
\end{abstract}

Keywords: territorial concession, industrial remains, company town 


\section{1.- Ubicación geográfica}

El poblado de San Antonio se encuentra ubicado a 400 metros sobre el nivel del mar en unos cerros donde discurren varios arroyos que desaguan rápidamente a las costas peninsulares y cuenta actualmente con unos 450 habitantes. La parte más antigua esta formada por manzanas irregulares, con construcciones del siglo XVIII, como la parroquia y otros edificios. Tiene asimismo manzanas más regulares, donde se encuentran la mayoría de los edificios construidos a finales del siglo XIX y principios del XX; también un trazo de manzanas, diferentes unas de otras, con construcciones del siglo XX, en su mayoría residenciales. Este núcleo conforma una mancha urbana compacta y rectangular entre la sierra, con una división natural por un arroyo y una artificial, que es la carretera transpeninsular. ${ }^{1}$

El poblado de El Triunfo se encuentra asimismo a 480 metros sobre el nivel del mar y tiene una población de aproximadamente 320 habitantes. La carretera transpeninsular divide el conjunto en dos partes. En la primera encontramos un trazo definido de calles, aunque con una variedad en las dimensiones de las manzanas, ocupadas con edificaciones del siglo XIX, de adobe y ladrillo con losas inclinadas. Alrededor aparecen vestigios de la minería, representados por dos chimeneas de ladrillos que nos acerca a la magnitud e importancia de esta población a finales del siglo XIX. Otro hito significativo es el panteón ingles, muestra de la colonización extranjera de la minería industrial en la región. Al Noroeste la traza urbana presenta manzanas de dimensiones amplias y homogéneas, con escasas construcciones. Su morfología permite identificar dos etapas en su crecimiento: la primera del siglo XIX, abarcando el $90 \%$ de su extensión actual y solo el 10\% del siglo XX. Esto indica que el núcleo urbano se fue abandonando a raíz del ocaso de la minería industrial y que en la primera década del siglo XX, las compañías marcharon y con ellas la población. ${ }^{2}$

\section{Contexto histórico}

En 1748 surge el primer antecedente de un asentamiento minero en la región sur de la península de la Baja California, El Real de minas de Santa Ana (primer centro minero de todo el Noroccidente del continente americano, desde el extremo peninsular californiano hasta Alaska). Posteriormente se fundan los centros mineros de El Triunfo y San Antonio, cercano a las minas del mismo nombre. La apertura de minas da origen a espacios inicialmente indefinidos como asentamientos, más bien conjuntos de construcciones rurales dispersas en la sierra y relacionadas estrechamente con las minas. La primera mitad del siglo XIX como la minería, principal actividad económica, no logra consolidar estructuras urbanas significativas hasta la llegada de las compañías mineras extranjeras, que dan un fuerte impulso, desarrollando la industria minera a gran escala.

La minería rudimentaria que se practica queda atrás al formarse sociedades mineras de capital nacional y extranjero, que contribuyen a perfeccionar las técnicas de extracción, introduciendo la máquina de vapor y construyendo tiros y socavones. Los espacios mineros cambian y se transforman en grandes espacios industriales, con almacenes, patios y edificios administrativos.

\footnotetext{
${ }^{1}$ La mayor parte de la información se ha obtenido del articulo Breve historia de los pueblos mineros de Baja California Sur, escrito por Flor Barreiro, Rocío Rochín y Gilberto Piñeda.

${ }^{2}$ La mayor parte de estos textos se componen de información obtenida del articulo Breve historia de los pueblos mineros de Baja California Sur escrito por Flor Barreiro, Rocío Rochín y Gilberto Piñeda.
} 
Historiadores como Ignacio Rivas menciona que el periodo entre 1878 y 1910 se caracteriza por una transformación radical de la explotación minero-metalúrgica, en base a la política económica de Porfirio Díaz y al impulso sostenido de las compañías extranjeras.

El establecimiento de las compañías mineras extranjeras trae consigo cambios significativos en las estructuras poblacionales y territoriales. Es importante señalar que las compañías mineras están condicionadas a dotar de infraestructura a los pueblos donde se asentaban sus trabajadores, configurando su estructura urbana e incorporando nuevas dinámicas en el territorio. Las concesiones otorgadas por el gobierno mexicano obligan a las compañías a instalar y construir su industria para su correcto funcionamiento, trazando nuevos caminos para tratar de establecer poblaciones permanentes para la ocupación de la península.

El Triunfo y San Antonio son dos claros ejemplos donde se desarrolla un proyecto urbano para consolidar la región. El territorio se vuelve productivo con una serie de construcciones industriales como minas, chimeneas y pequeñas fundiciones, conectadas mediante un circuito ferroviario de 10 kilómetros, con varios puentes. Las poblaciones devienen dinámicas con esas diferentes piezas que conforman una colonia industrial bien establecida. Su legado supone hoy una extraordinaria riqueza de ruinas industriales y trazados urbanos, que necesitan ser valorados y restaurados, como muestra de la industrialización de estos territorios tan alejados del centro de México. Pero no por su lejanía son menos importantes, ya que cuentan con una identidad propia.

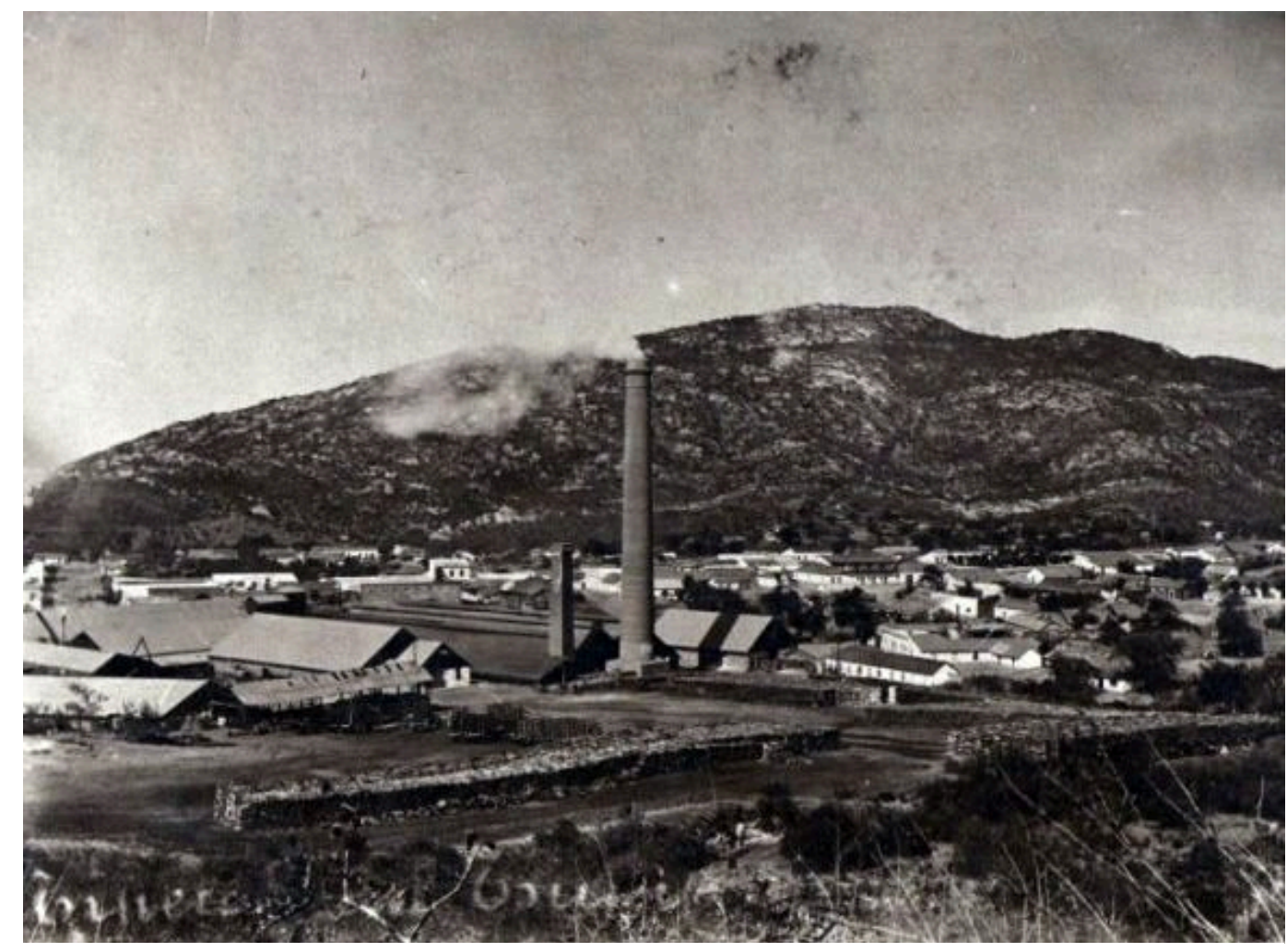

Figura 1. Fotografía de la población industrial de El Triunfo, que se asemeja a una company town con sus fundiciones de metales, bodegas y viviendas obreras. Fuente: El Triunfo. Pueblo Histórico que se niega a morir. Bellezas de Sud California. 


\section{Desarrollo urbano e influencia de las compañías mineras}

Aproximadamente alrededor de 1865 empieza sus actividades la compañía The Triunfo Silver Mining and Commercial Company, resultado de la unión de la Triunfo Gold and Silver Company de San Francisco y la Molineña Silver Mining Company de Filadelfia, y que posee minas de plata y empresas dedicadas al comercio en toda la península de Baja California.

Estas compañías ya cuentan con un sistema completo de extracción, beneficio de los metales y exportación marítima hacia Estados Unidos. La propiedad concesionada por el gobierno mexicano al capital extranjero se sitúa en el Distrito Minero de San Antonio y cuenta con las minas La Canoa, La Molineña, La Valenciana, La Mendoceña, El Carmen y La Triunfanta.

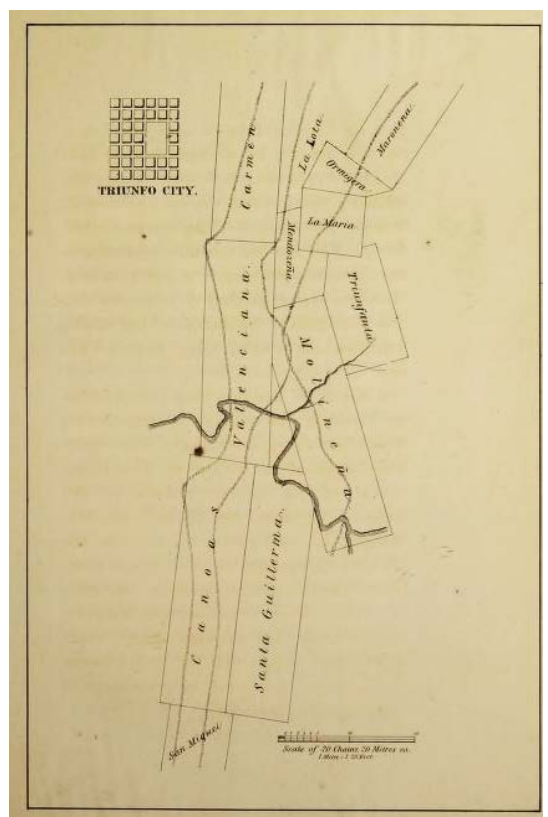

Figura 2. Plano urbanístico de El Triunfo en 1866. Fuente: "Report on the property of the Triunfo silver mining and commercial company of Lower California, with some account of the mines of the peninsula and observations on the mode of beneficiating silver ores" realizado por El Triunfo silver mining and commercial company of Lower California.

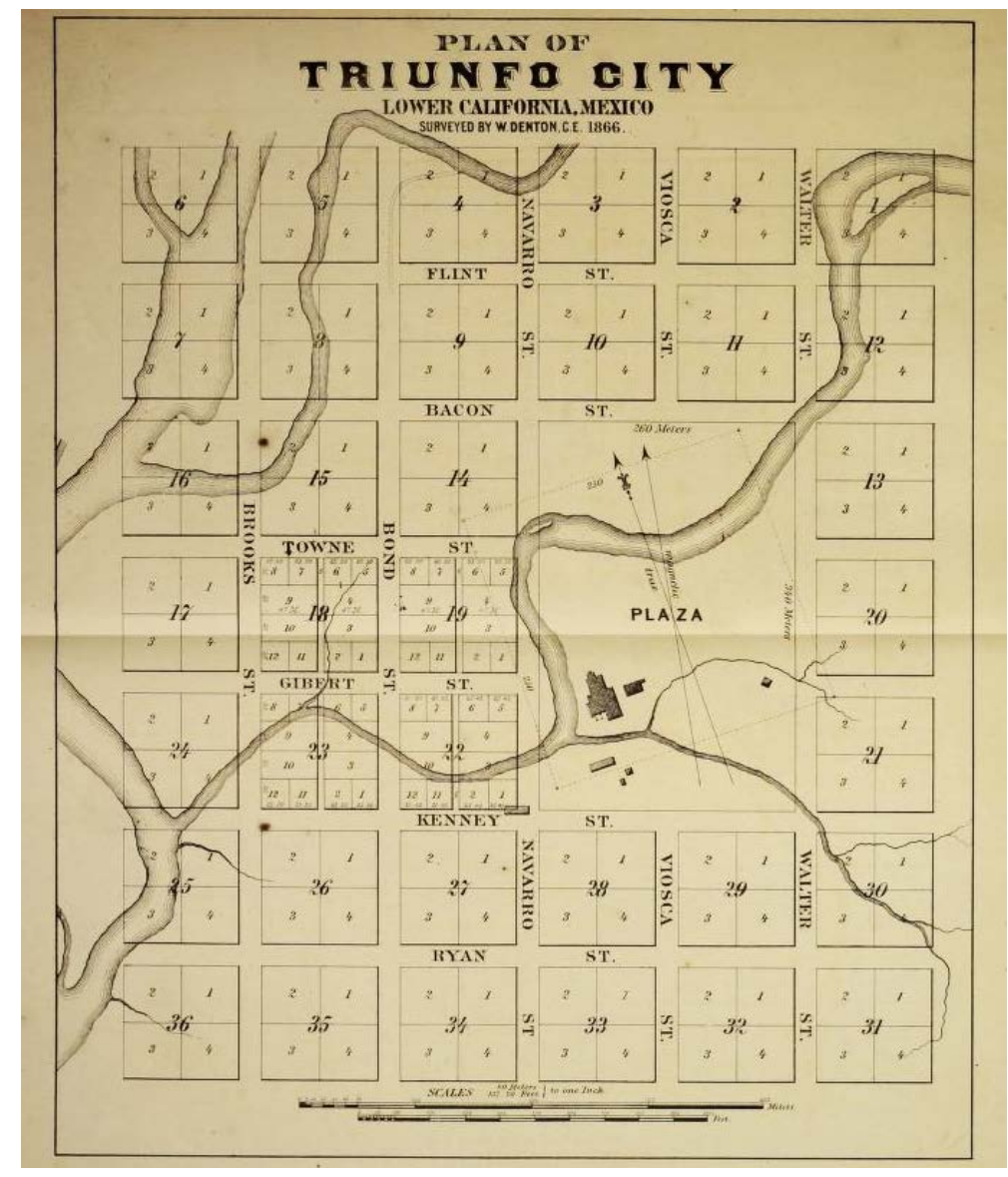

La compañía de mayor impacto en la región es El Progreso Mining Company de capital estadounidense, que se establece en 1878 y se caracteriza por un fuerte impulso en tecnología, junto a una gran cantidad de fundos mineros entre El Triunfo y San Antonio, aproximadamente 1,196 hectáreas. La mayor influencia de la Compañía El Progreso se refleja en El Triunfo, donde se ubica su hacienda de beneficio. La consolidación de la industria minera trae el crecimiento de la población, y se estima que en 1890 hay más de 4000 habitantes, llegando pocos años después a 10,000 habitantes. Esto favorece la transformación de las relaciones sociales, la organización político administrativa y la imagen del poblado. Ignacio Rivas Hernández hace una descripción detallada de la conformación espacial de El Triunfo, destacando la ubicación de las zonas habitadas por los distintos grupos de población. Se compone de un área central donde se localizan los comercios. Otros grupos de viviendas se sitúan cercanas a los talleres y oficinas de la compañía El Progreso, construidas de madera con base de ladrillos, y con uno y dos pisos y jardines alrededor. Este grupo de viviendas se conoce entre los pobladores como la colonia inglesa. 
En los límites del área central se construyen casas de piedra y ladrillo, que pertenecen a la población foránea, que llega a trabajar en la minería y el comercio principalmente. En la pequeña periferia se establecen viviendas de madera de los obreros de menor categoría, que trabajan en las minas. En esta etapa se delimita la forma de la estructura urbana del conjunto, con calles rectas ordenadas y edificios de ladrillo. ${ }^{3}$

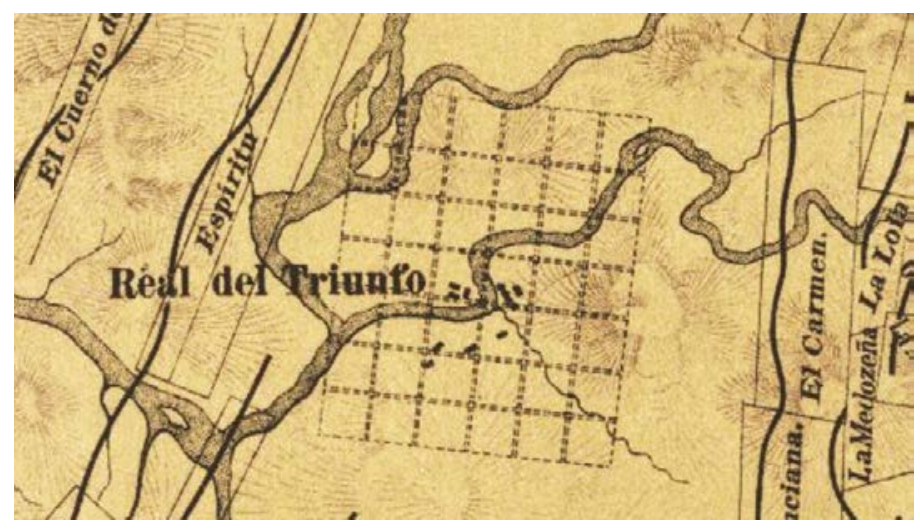

Figura 3. Acercamiento al trazo urbano de El Triunfo. Fuente: Plano geológico minero de 1889 del real de San Antonio y El Triunfo de la Baja California. 217-CGE-7221-A. Obtenido de la Mapoteca Nacional Orozco y Berra colección general.

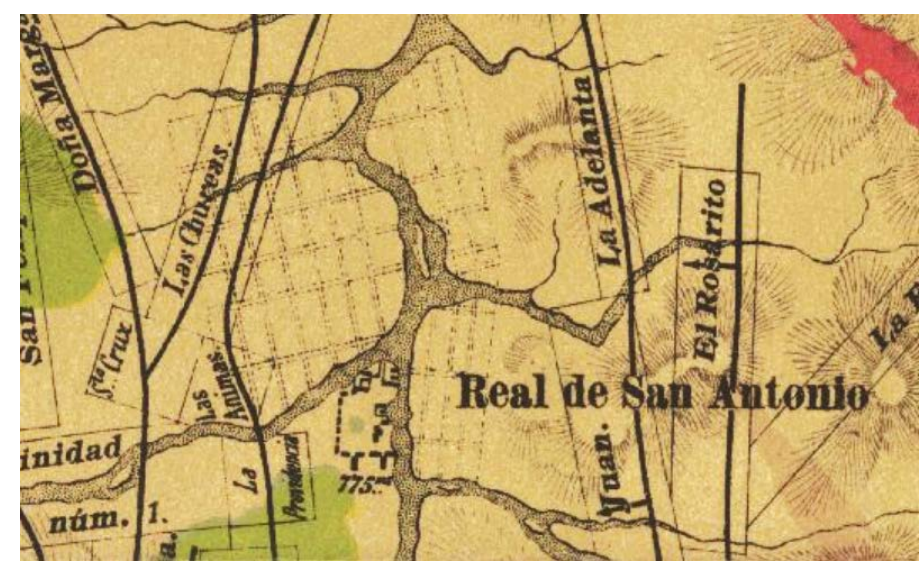

Figura 4. Acercamiento al trazo urbano de San Antonio. . Fuente: Plano geológico minero de 1889 del real de San Antonio y El Triunfo de la Baja California. 217-CGE-7221-A. Obtenido de la Mapoteca Nacional Orozco y Berra colección general.

Al revisar el plano de El Triunfo de 1866 encontramos 36

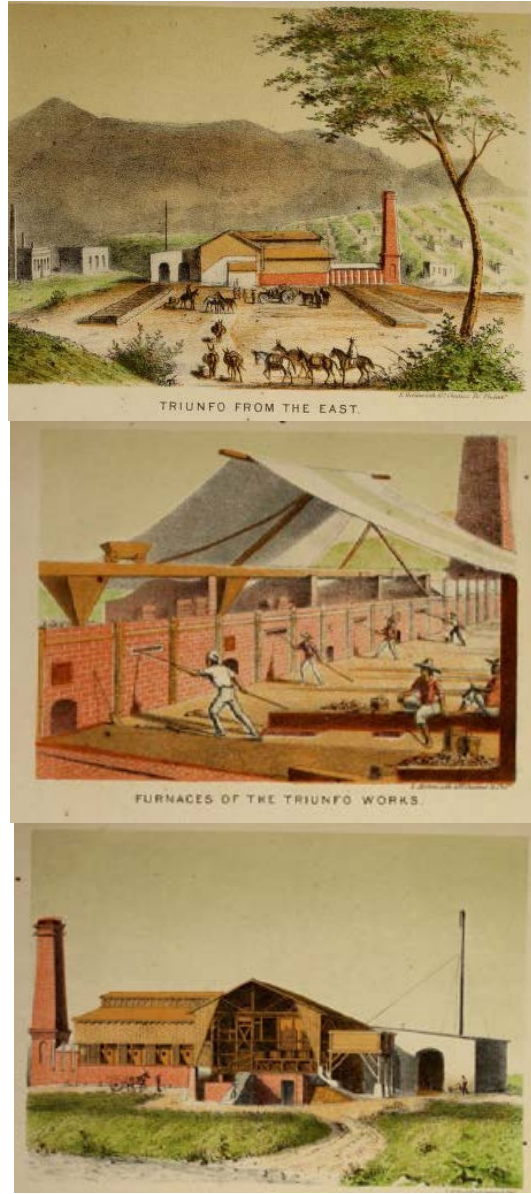

Figura 5. Imágenes de las áreas industriales de El Triunfo. Fuente: "Report on the property of the Triunfo silver mining and commercial company of Lower California, with some account of the mines of the peninsula and observations on the mode of beneficiating silver ores" realizado por El Triunfo silver mining and commercial company of Lower California. manzanas cuadradas alrededor de un área central rectangular mayor, donde se coloca el complejo industrial. La propuesta no llega a desarrollarse por completo, pero se pueden identificar algunas trazas que coinciden con el proyecto. Se aprecia una subdivisión en las manzanas localizadas a un costado del área industrial, que se componen de comercios y servicios. La retícula ortogonal entra en decadencia al agotarse el mineral, con el abandono de las compañías mineras.

\footnotetext{
${ }^{3}$ La mayor parte de estos textos se componen de información obtenida del articulo Breve historia de los pueblos mineros de Baja California Sur escrito por Flor Barreiro, Rocío Rochín y Gilberto Piñeda.
} 
Se propone un método de análisis que muestra la evolución urbana para destacar el legado patrimonial.

La consolidación de las compañías entre 1878 a 1895 ayuda a su crecimiento poblacional. Pero el auge dura poco, ya que en los primeros 10 años del siglo XX las dos poblaciones se abandonan ${ }^{4}$.
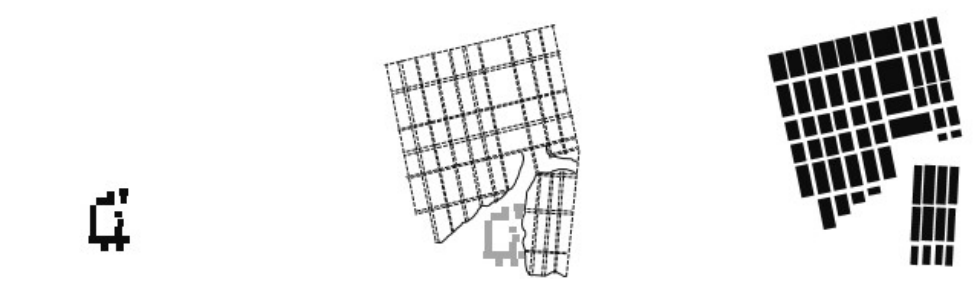

Evolución urbana de San Antonio

Evolución urbana de El Triunfo
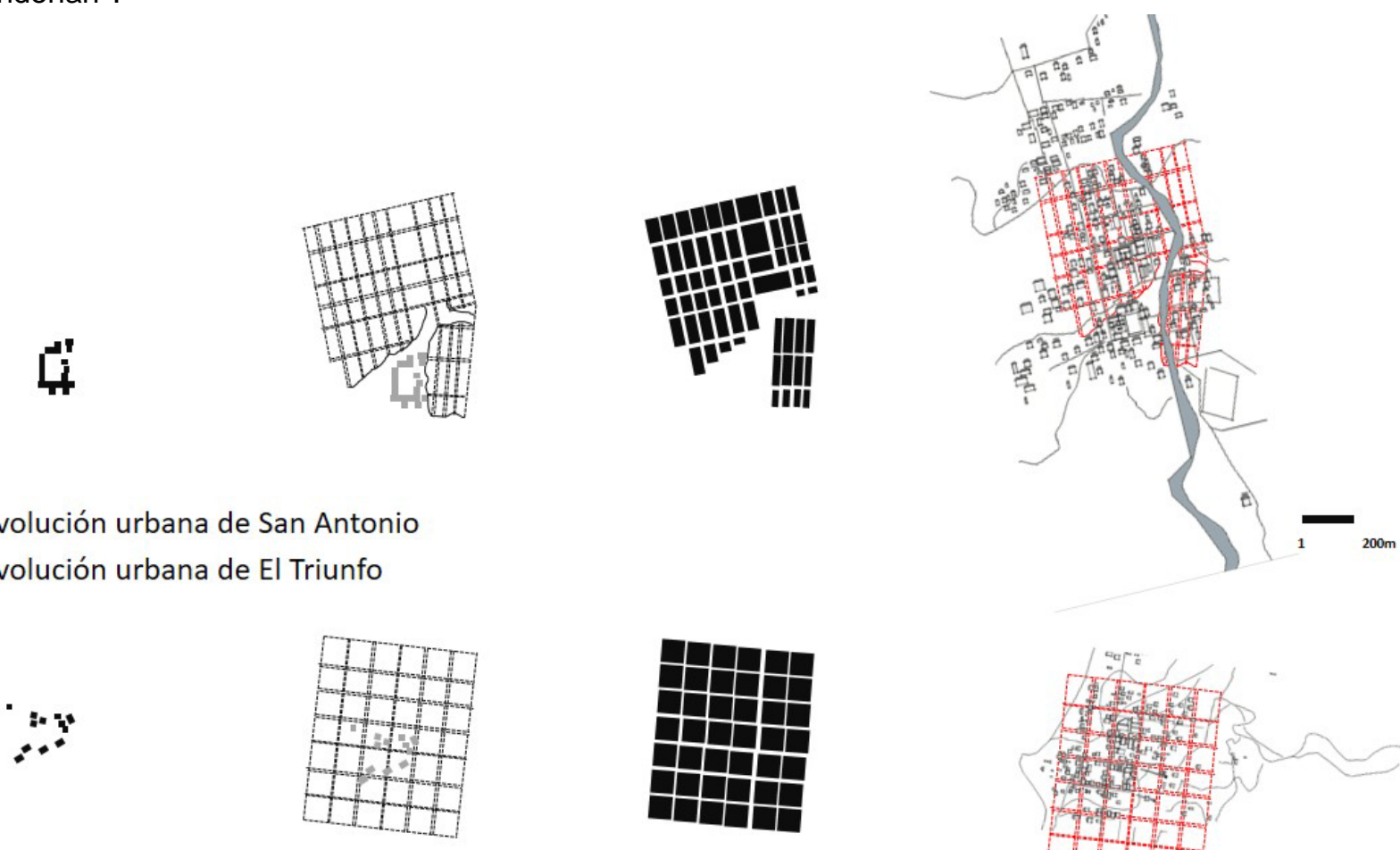

SIGLO XVIII

SIGLO XIX

SIGLO XX

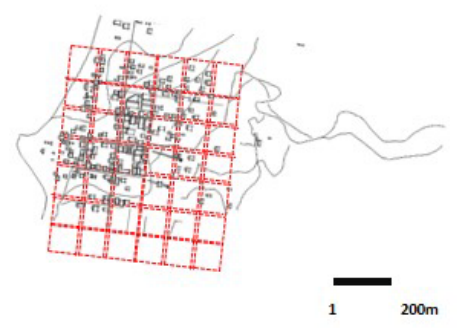

SIGLO XXI

Figura 6. Esquemas de la evolución urbana de El Triunfo y San Antonio. Fuente: Elaboración propia

\begin{abstract}
Figura 7. Esquema de reconocimiento

urbano que nos muestra a través de la sobre posición de planos fundacionales y las fotos aéreas la poca consolidación del proyecto de $\mathrm{El}$ Triunfo. Fuente: Elaboración propia en base al plano de 1870.
\end{abstract}
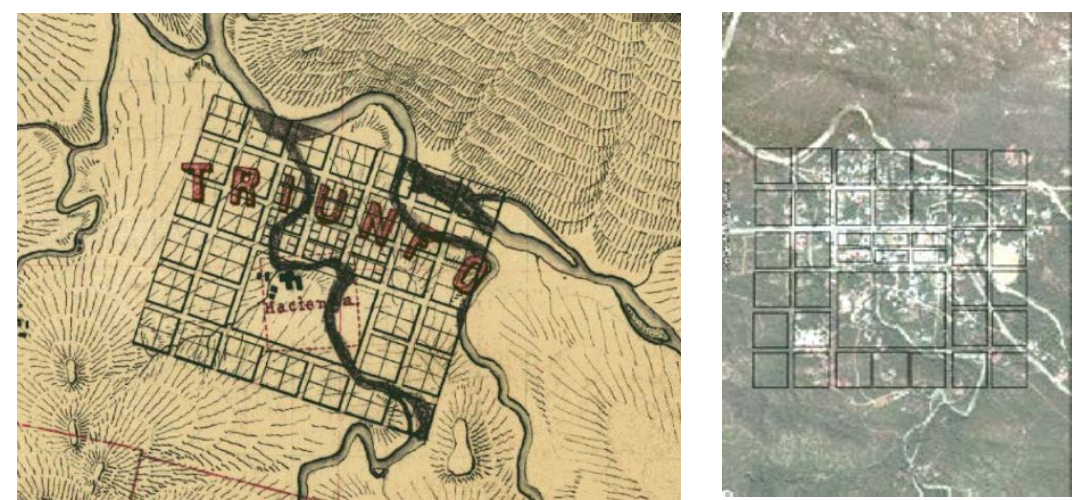

En el caso de la población de San Antonio, se intenta estructurar el centro histórico con una retícula ortogonal que liga la parte antigua con la nueva, pero al igual que en El Triunfo el proyecto no llega a desarrollarse por completo, quedando los trazos incompletos en su inserción en el territorio. Pero no por esto el sitio es menos valioso, ya que cuenta con importantes vestigios de la minería industrial y sus construcciones pueden todavía ser revitalizadas para resaltar su patrimonio.

\footnotetext{
${ }^{4}$ Breve historia de los pueblos mineros de Baja California Sur. Una historia urbana de los pueblos de San Antonio y el Triunfo. Autores: Flor Barreto, Rocío Rochin y Gilberto Piñeda.
} 


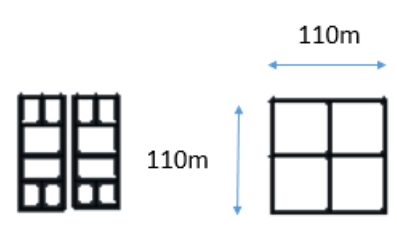

Figura 8. Manzanas regulares del pueblo minero de El Triunfo. Fuente: Elaboración propia en base a los planos fundacionales.
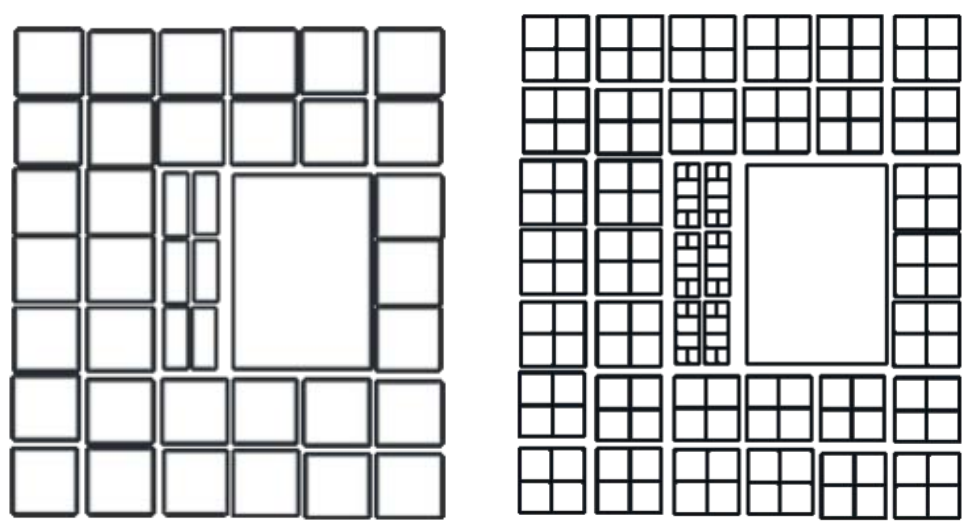

Figura 9. Proyecto de El Triunfo, plano de 1866 y 1870 del pueblo minero de El Triunfo. Fuente: Elaboración propia en base a los planos fundacionales.

Las construcciones son en su mayoría de finales del siglo XIX, vestigios de la minería industrial representadas en dos iconos de la región, las dos chimeneas La Ramona y La Julia, que siguen en pie y cuyo diseño se atribuye al francés Gustav Eiffel. Actualmente las dos poblaciones no llegan a los 800 habitantes y sus trazados urbanos y ruinas industriales están gravemente deterioradas, a pesar de los intentos en los últimos años del gobierno de Baja California Sur de incentivar la zona a través de programas de turismo cultural.

En 1903 E. O. Ellison, comisionado especial de Los Angeles Herald, publica en la edición número 257 del periódico el artículo "Gold and silver mines of Lower California. The Cradle of the Great Mining Industry on the Shores of the Pacific, Where the Precious Metals Were Obtained in the Days Before the Mission Fathers Came", donde describe detalles de la región minera y el desarrollo que implementan las compañías. Habla de un centro minero moderno con chimeneas, patios industriales, bodegas y casas de madera estilo americano, donde viven los intendentes y oficiales. Hace mención a la concesión territorial otorgada por el gobierno de Benito Juárez a la compañía El Progreso Mining Company y como ésta se va haciendo con más terreno para explotar las minas. El paternalismo de la compañía hacia el pueblo es muy notorio ya que la población depende exclusivamente de la empresa.
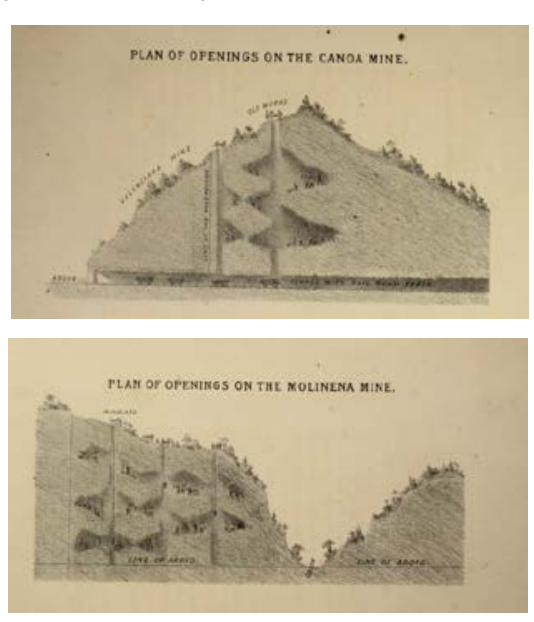

Figura 10. Imágenes de las minas de El Triunfo. Fuente: Report on the property of the Triunfo 1866.

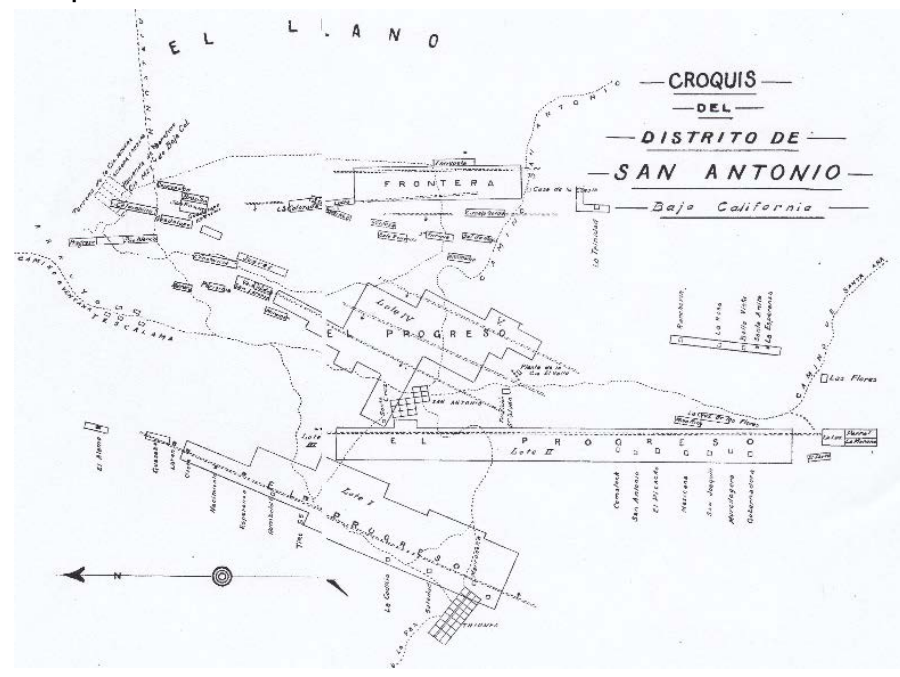

Figura 11. Plano del distrito minero de San Antonio. Fuente: Instituto Geológico de México. Exploración geológica en la Baja California. 


\section{Del auge minero a los pueblos fantasmas}

El florecimiento económico y urbano de San Antonio y El Triunfo pone de manifiesto un periodo de consolidación en su estructura territorial con la explotación minera a gran escala. Es importante mencionar que este sitio es, a finales del siglo XIX, un potente centro minero, que cuenta con moderna tecnología para la extracción, con fundidoras, molinos, motores de energía, almacenes, un circuito de ferrocarril y laboratorios superiores a todo lo que existe en la costa del Pacifico. Las compañías mineras se benefician de la localización geográfica, ya que el mineral se embarca rápidamente en las costas, ya sea en el puerto de La Paz o en Bahía Ventana, en un muelle construido por la compañía. Esto muestra la importancia de este lugar y la fuerte inversión del capital extranjero en la península.

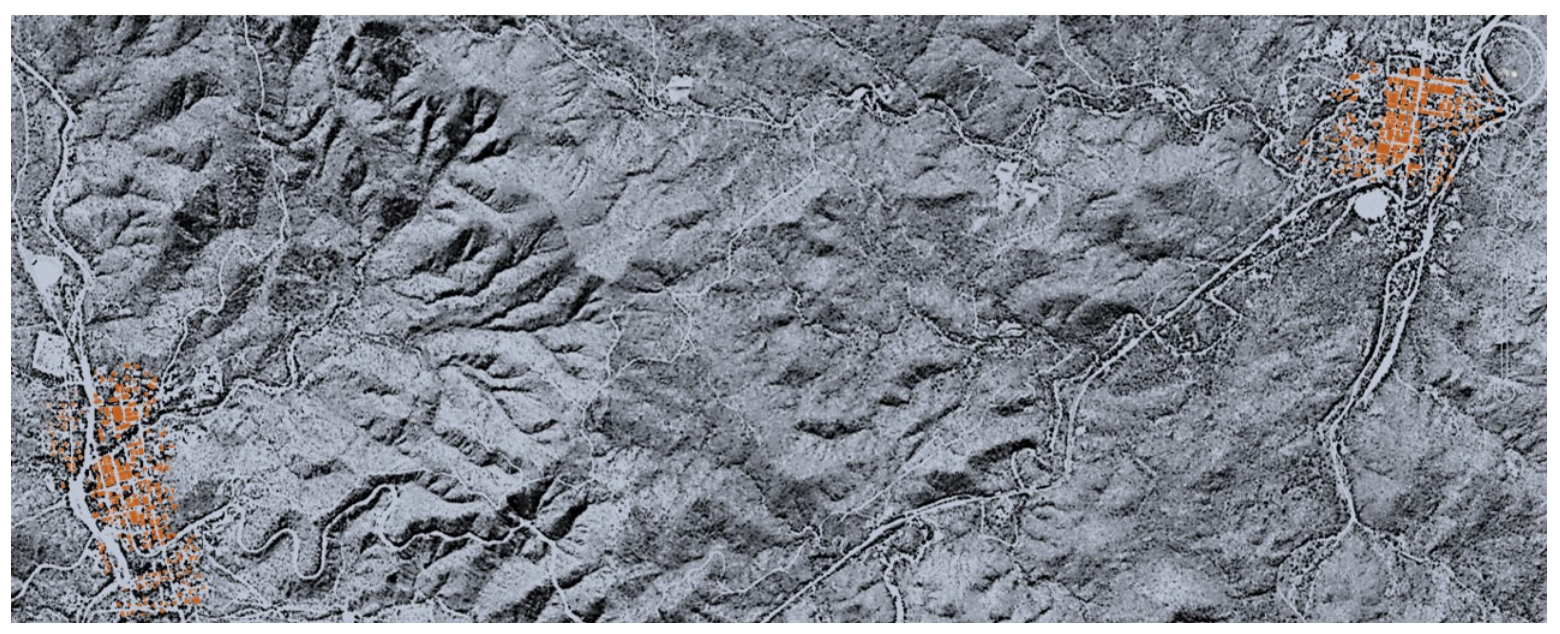

Figura 12. Imagen de satélite que muestra las poblaciones actuales de El Triunfo y San Antonio que se encuentran a 7 kilómetros aproximadamente una de otra. Fuente: Elaboración propia

En las primeras décadas del siglo XX la economía y la actividad minera decaen. Esto lleva al abandono paulatino de los centros de población, y a su deterioro progresivo. La post industrialización trae consigo inevitables consecuencias para las denominadas company towns, ya que la minería que al considerar agotados los yacimientos, éstos se cierran al plantearse los dueños del capital la rentabilidad de la explotación. Las compañías dejan atrás pueblos enteros y construcciones industriales sin importarles el futuro de la población. Por eso el compromiso es ahora nuestro, de los arquitectos, defensores del patrimonio, historiadores y, en general, de la sociedad civil, interesada en revalorizar el patrimonio industrial de Baja California Sur, para rescatar los vestigios de la era industrial y revindicar la identidad perdida de estos pueblos. Para ello resulta imprescindible un plan de manejo para esta región, una especie de distrito histórico de la península y un museo de sitio para iniciar el proceso de una nueva catalogación del rico legado industrial y su puesta en valor a través del turismo cultural.

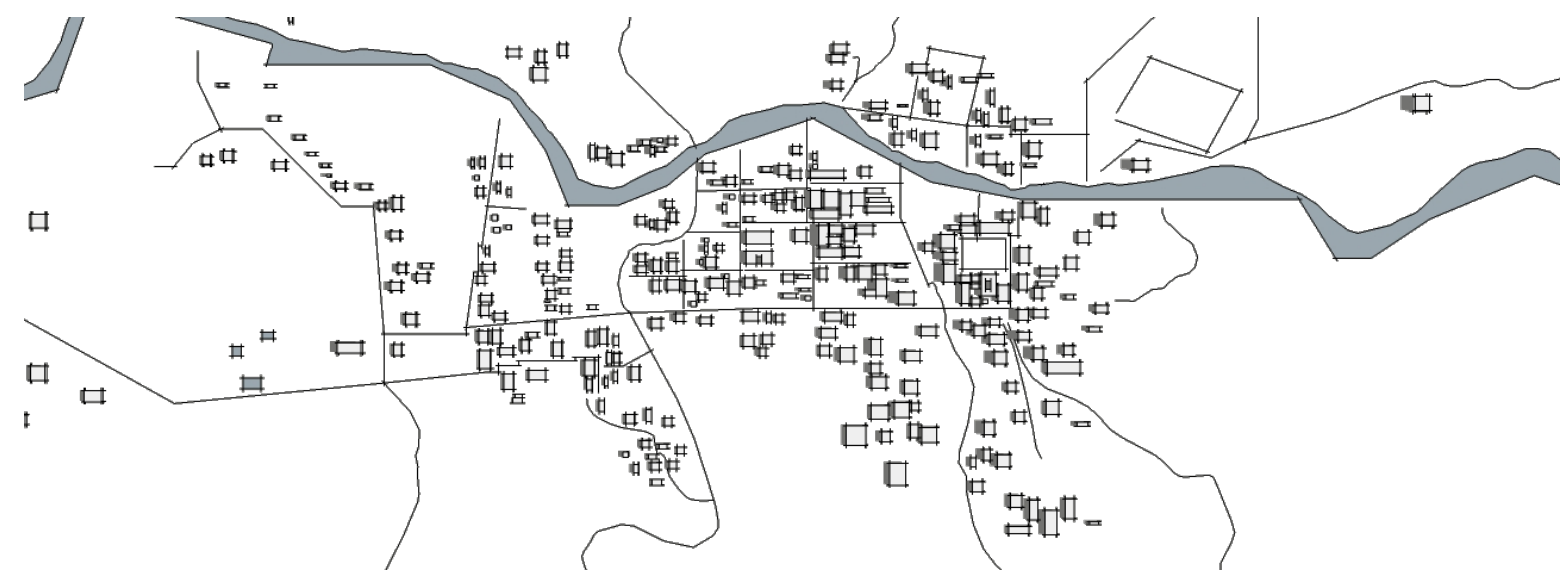


Figura 13. Dibujos de las manchas urbanas actuales de El Triunfo y San Antonio. Se puede apreciar su localización sobre los arroyos de la sierra donde se establecen las poblaciones mineras. Fuente: Elaboración Propia

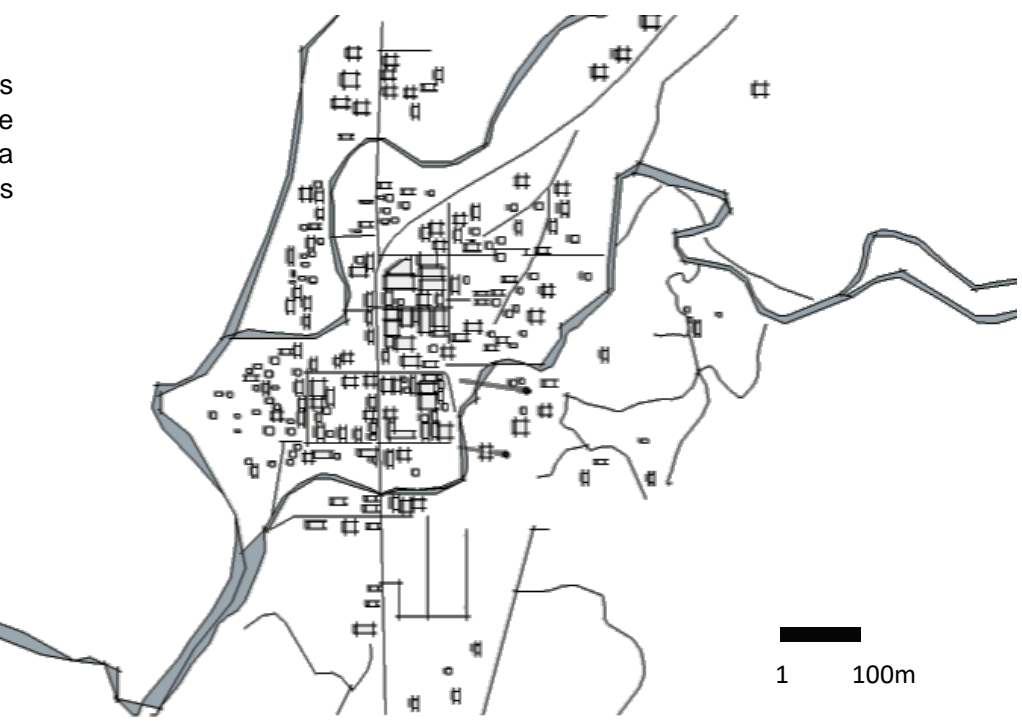

\section{5.- Los vestigios y la oportunidad de un parque patrimonial}

Las ruinas y vestigios en territorios post-industriales en los últimos 35 años han sido objeto de reflexión, y están siendo capaces de revertir situaciones de abandono, a través del turismo cultural en todo el mundo.

Un parque patrimonial se define como un proyecto que privilegia la construcción de una imagen, que otorga identidad al territorio, donde el patrimonio y los recursos culturales y naturales se combinan, exponen, aumentan y promueven intencionalmente para formar un paisaje convenido, que cuenta la historia de dicho territorio y sus residentes. ${ }^{5}$

Creemos que esta herramienta podría resaltar el patrimonio industrial de la región, y que las nuevas concesiones mineras a capital canadiense ponen en riesgo el legado de este territorio. La planificación y ordenamiento territorial debe incluir un proyecto patrimonial en la zona para reactivar el desarrollo en estas comunidades olvidadas y promover la preservación de los recursos culturales y del paisaje.

Haciendo referencia al contexto internacional, el caso de Cataluña con su sistema de colonias textiles a lo largo del rio Llobregat es un ejemplo de la gestión inteligente del patrimonio y el impulso del desarrollo regional. La investigación del profesor Pere Vall "El sistema de colonias textiles del Baix Berguedá. Genesis y revaloración", habla de la colonia textil como una pieza importante del paisaje industrial catalán y de su estratégica localización a lo largo del eje de los ríos, consolidándose como motores económicos e instrumento de progreso social a finales del siglo XIX y principios del siglo XX. Este estudio es muy valioso ya que plantea una alternativa para las sociedades post-industriales recuperando los territorios productivos obsoletos, detectando un rico patrimonio de quince fábricas a lo largo de veinte kilómetros por el rio Llobregat. ${ }^{6}$

En el norte de México, así como en muchos territorios del mundo, existen huellas muy marcadas de la industrialización y la península de Baja California no es la excepción. Aquí el capitalismo extranjero desarrolla regiones enteras y después las abandona dejando restos de poblados que hoy en día pueden narrar la historia industrial de un territorio tan peculiar como éste. Es importante valorizar los trazados urbanos que inician la modernidad en estas latitudes para contribuir al conocimiento de estos lugares.

\footnotetext{
${ }^{5}$ Definición empleada en "Pasajes culturales: El Parque patrimonial como instrumento de revalorización y revitalización del territorio”. Escrito por Leonel Pérez Bustamante y Claudia Parra Ponce.

${ }^{6}$ De Colónies téxtils a Parc Fluvial. El sistema de Cólonies Téxtils del Berguedá. Génesi i revaloració.

Escrito por Pere Vall i Casas. Colección: Cultura, Técnica y Sociedad.
} 


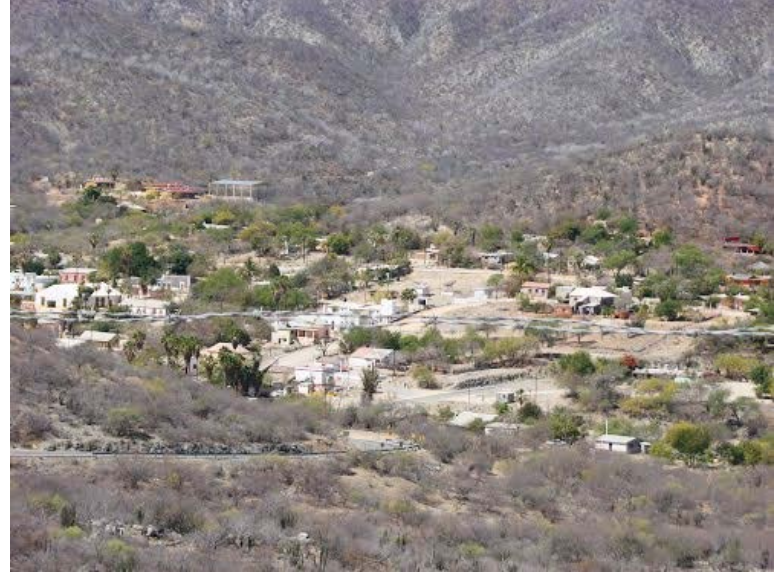

Figura 14. Vista del poblado de San Antonio. Fuente: https://en.mexico.pueblosamerica.com

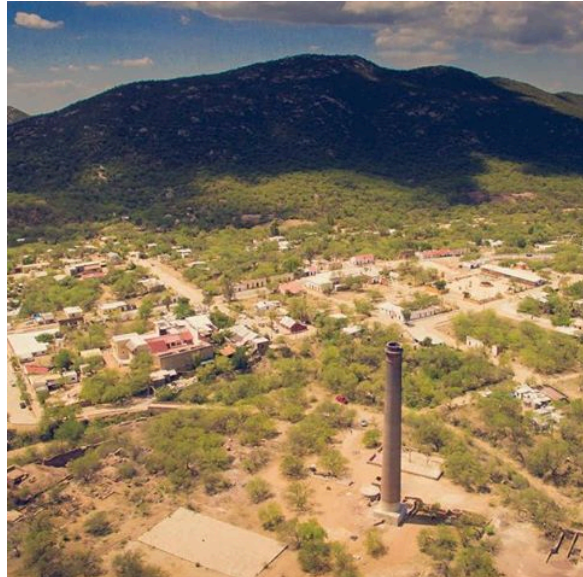

Figura 15. Vista del poblado de El Triunfo. Fuente: https://en.mexico.pueblosamerica.com

Existen iniciativas como la de la asociación civil Corredor Histórico Carem, para el rescate de la emblemática chimenea de El Triunfo. Este organismo trabaja en la preservación y revitalización del patrimonio histórico con el objetivo de presentar a la sociedad el rico legado que existe en la península de Baja California.

Este pequeño artículo pretende recopilar la información más destacada de este lugar para resaltar la importancia de El Triunfo y San Antonio a finales del siglo XIX y principios del XX, incluyendo estos distritos históricos en las actuales políticas urbanas.

Elementos de valor excepcional como chimeneas, patios industriales con maquinaria al aire libre, puentes de ladrillo, edificios en ruinas, casas y minas, pueden integrarse en un proyecto de regeneración industrial con un beneficio cultural y social significativo. A continuación se muestra la ocupación urbana de los poblados y su arquitectura, junto al patrimonio actual y bocetos de la integración de los vestigios industriales de El Triunfo y San Antonio en Baja California Sur México.
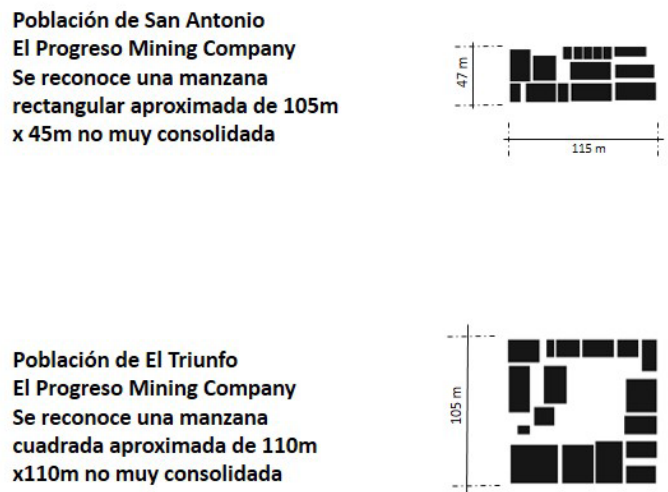
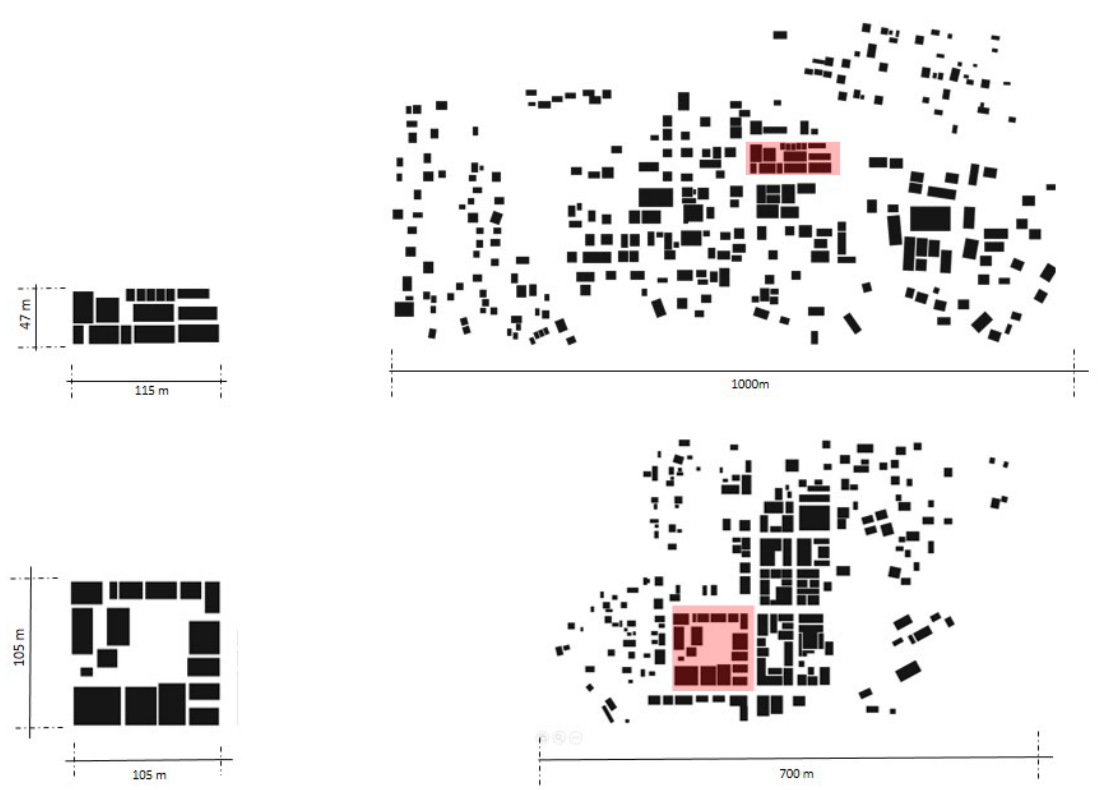

Figura 16. Esquemas de ocupación actual y manzana más consolidada. Fuente: Elaboración propia 


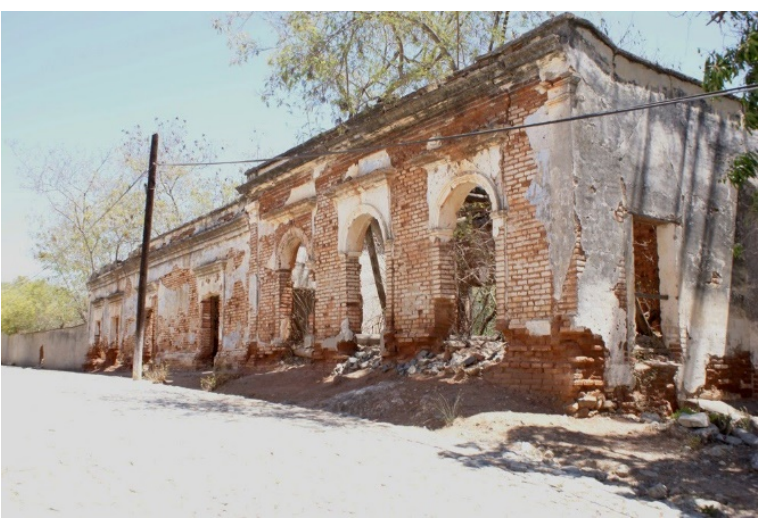

Figura 17. Ruinas en San Antonio. Fuente: Fotografía de Martin Cota. http://www.panoramio.com/

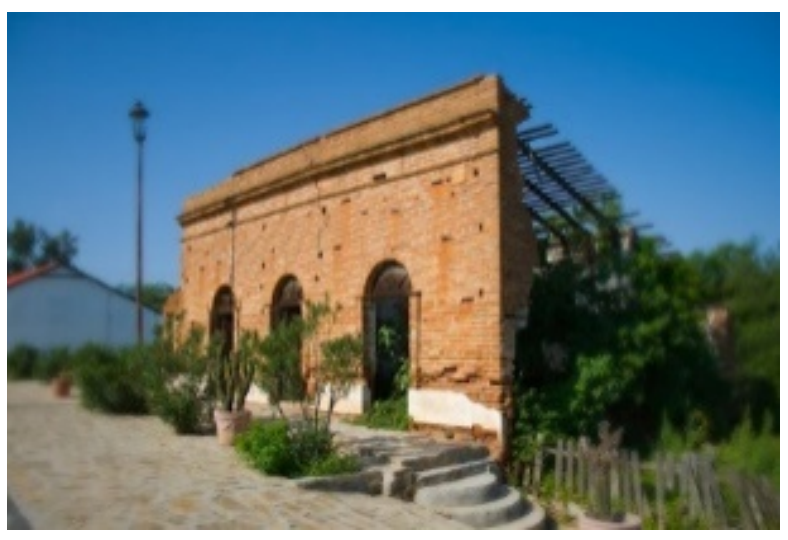

Figura 18. Ruinas industriales en el Triunfo Baja California Sur. Fuente: www.bajachallengetours.com 


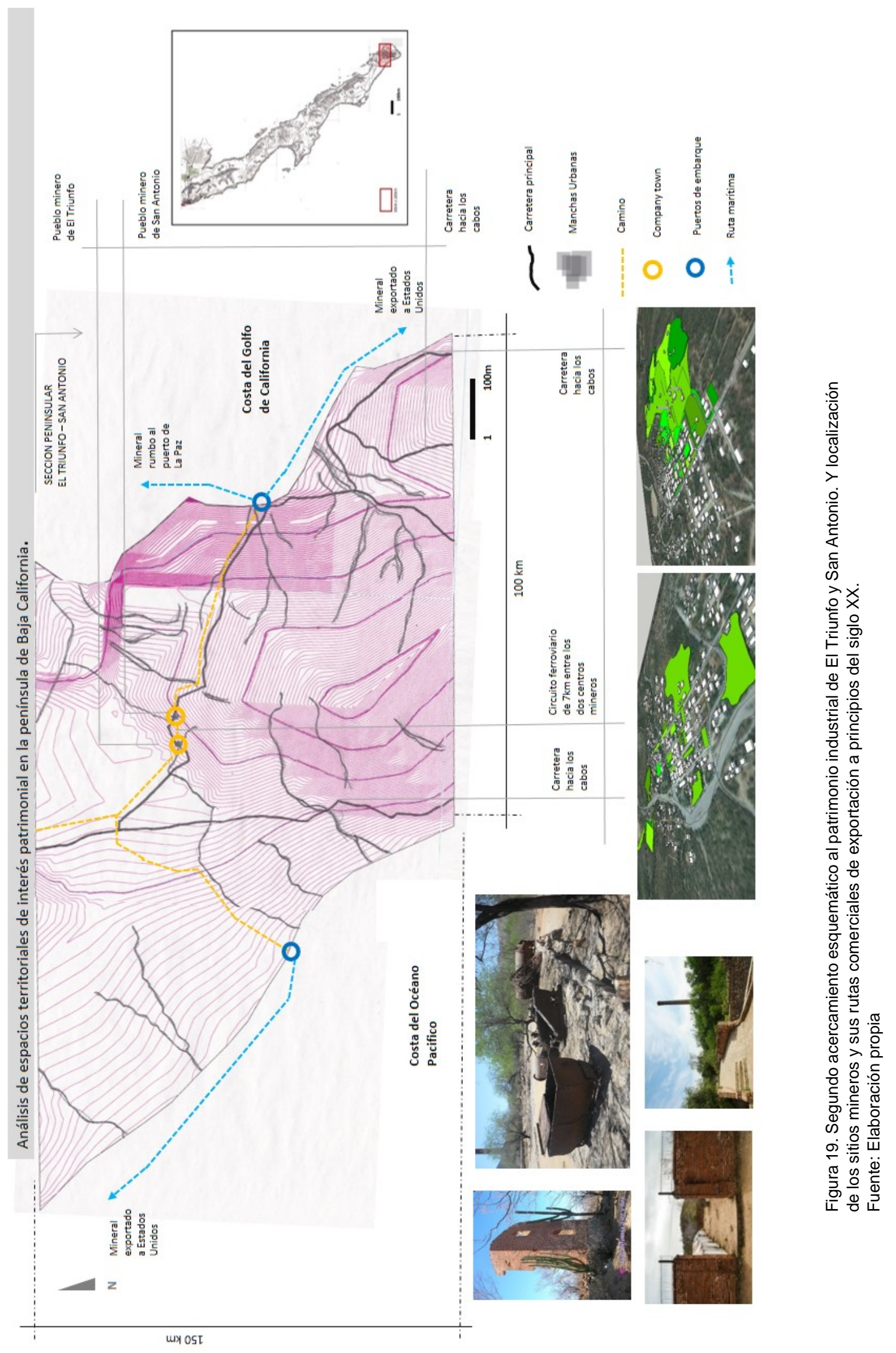


Para defender nuestra principal hipótesis, creemos que un primer acercamiento podría ser una clasificación de los vestigios industriales, para comprobar los ricos recursos que contiene esta región y poder valorizar su identidad industrial. Para finalizar se agrupa en la siguiente tabla la información recopilada en esta primera etapa.

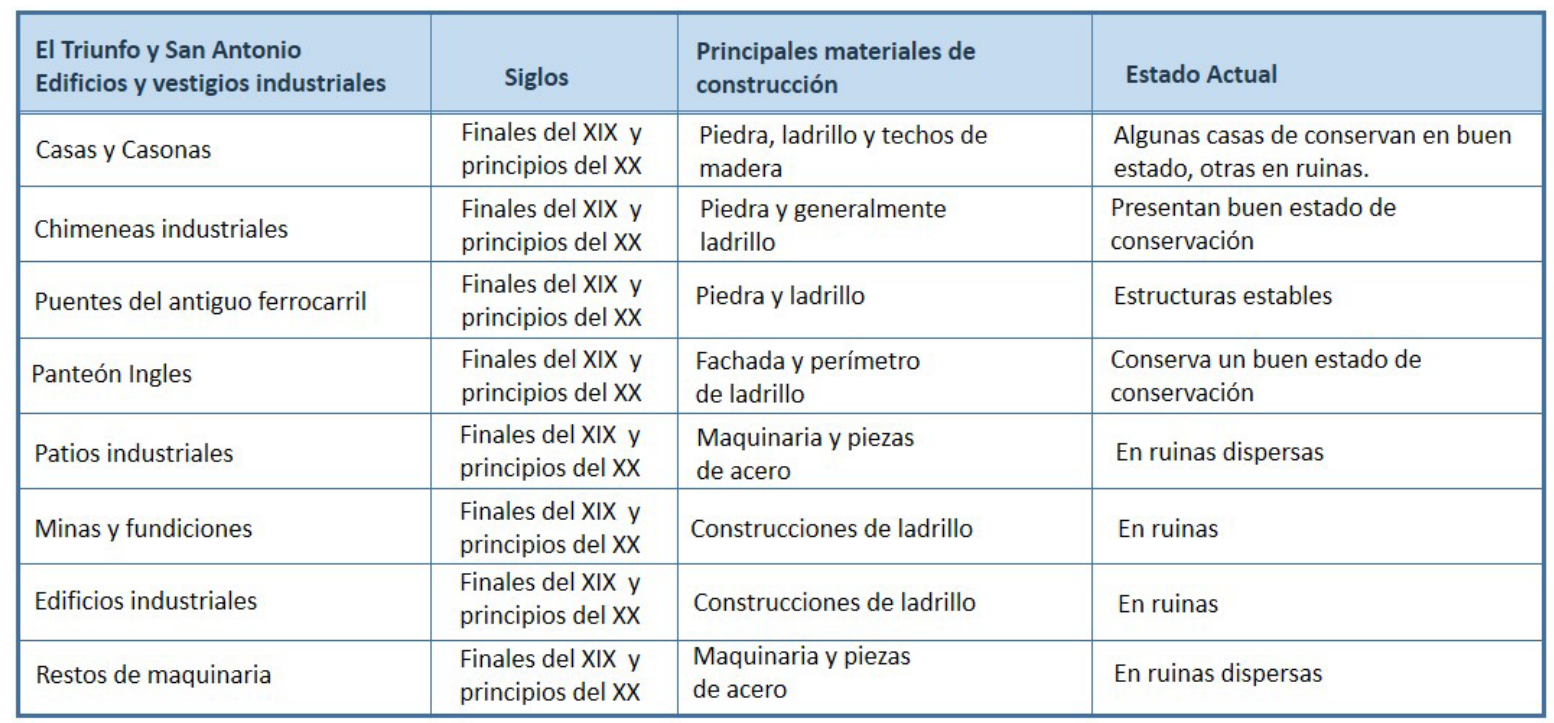

Figura 20. Tabla que agrupa los principales vestigios industriales de El Triunfo Y San Antonio. Fuente: Elaboración propia

Se llega a la conclusión que este tipo de trazados industriales tienen influencia extranjera, ya que las compañías importan los proyectos mineros y desarrollan estructuras económicas productivas donde nada existía. El periodo de auge de estos núcleos urbanos es relativamente corto, pero fue suficientemente importante para dejar un valioso patrimonio industrial desapercibido actualmente. Por eso, creemos firmemente en las posibilidades patrimoniales de estos sitios y en sus repercusiones positivas para un territorio olvidado como lo es la península de Baja California.

\section{Bibliografía}

Barreto, Flor (2013). "Valoración de los centros históricos. Tiempo, espacio y patrimonio: El caso de la ciudad de La Paz, Todos Santos, El Triunfo y San Antonio". Universidad Autónoma de Baja California Sur, Área de Conocimiento de Ciencias Sociales y Humanidades. Departamento Académico de Economía. 2013.

Barreto, Flor y Rocío Rochìn (2013). "Una historia urbana de los pueblos de San Antonio y El Triunfo". Breve Historia de los pueblos mineros de Baja California Sur. Con colaboración de Gilberto Piñeda y editado por Gerardo Ceja de forma impresa en el periódico El Sudcaliforniano, de La Paz, B. C. S.

Busto, Karina (2015). "Historical Archaeology of Baja Califronia Sur" Pacific Coast Archaeological Society Quarterly 51(3\&4):91-116 
Carel, Frederik H. (1977). "My journey to the peninsula of baja california" The Journal of San Diego History. San Diego historical society quarterly. Summer 1977, Volume 23, Number 3. Editado por James E. Moss y Thomas L. Scharf.

Díaz, Fernando (2010) "Trazas, mojones y poblados del norte de traslasierra. Elementos para la definición de una estructura territorial" Revista Identidades, territorio proyecto y patrimonio. Laboratorio Internacional de Paisajes culturales. Número 2. Barcelona 2010.

Ellison, E.O. (1903). "Gold and silver mines of lower california The Cradle of the Great Mining Industry on the Shores of the Pacific, Where the Precious Metals Were Obtained in the Days Before the Mission Fathers Came". Los Angeles Herald, Number 257, 21 June 1903

Montgomery, L Bond (1866). "Report on the property of the Triunfo silver mining and commercial company of Lower California, with some account of the mines of the peninsula and observations on the mode of beneficiating silver ores" publicado por Phil. King \& Baird realizado por El Triunfo silver mining and commercial company of Lower California.

Pérez, Leonel y Parra Claudia (2004). "Paisajes culturales: El parque patrimonial como instrumento de revalorización y revitalización del territorio". Revista Theoria, Vol. 13: 9-24, 2004

Sabatè, Joaquín (2004). "Paisajes Culturales. El patrimonio como recurso básico para un nuevo modelo de desarrollo". DUOT. Urban 9. Primera época. pp. 8-29. Barcelona España 2004.

Vall, Pere. (1999). "De colonies textils a parc fluvial. El sistema de colonies textils del Baix Bergueda. Genesi y revaloracio." Col-leccio:Cultura, técnica y Societat. Enginyers Industrials de Catalunya. Marcombo Boixareu Editores. Barcelona 1999. 